\title{
Impetigo contagiosa: an interesting and a very rare finding in a newborn
}

\author{
Deepak Sharma, Srinivas Murki, Tejo Pratap
}

Department of Neonatology, Fernandez Hospital, Hyderabad, Andhra Pradesh, India

\section{Correspondence to}

Dr Deepak Sharma, dr.deepak.rohtak@gmail.com

Accepted 6 April 2014

\section{DESCRIPTION}

A full-term male baby with a birth weight of $4.2 \mathrm{~kg}$, large for gestation age, was born to a primigravida mother through caesarean section. The baby was admitted to the neonatal intensive care unit in view of respiratory distress for which he was started on oxygen support. The mother's antenatal history was significant for gestational diabetes mellitus (controlled through insulin). Maternal history was not suggestive of any fever in the last week of pregnancy or prolonged rupture of membrane or foul-smelling discharge.

Antenatal scan was normal. The baby was diagnosed to have reddish desquamation around perioral area, which were painful (figures 1 and 2). He was evaluated with sepsis screening and blood culture in view of suspected sepsis, and was started on antibiotics. Swab culture was sent for bacterial and fungal growth. On day 3, the baby developed honey-coloured crusting around perioral area which confirmed the diagnosis of impetigo contagiosa (figures 3-5). Blood and swab cultures showed no growth. The baby was discharged in good condition and is now in follow-up.

Impetigo is defined as an infection of the epidermis by the microorganism. It is mainly seen in infants after the age of 2 months. This is a very serious neonatal infection which needs to be treated aggressively with antibiotics without waiting for laboratory reports. It is classified into two forms: non-bullous/impetigo contagiosa and bullous impetigo. ${ }^{1}$ The most common causative organisms are Staphylococcus aureus and group A $\beta$ haemolytic streptococci (Streptococcus pyogenes). ${ }^{2}$ It generally presents as small blisters which rupture and spread (impetigo contagiosa) or erythematous areas. The diagnosis is mainly based on clinical

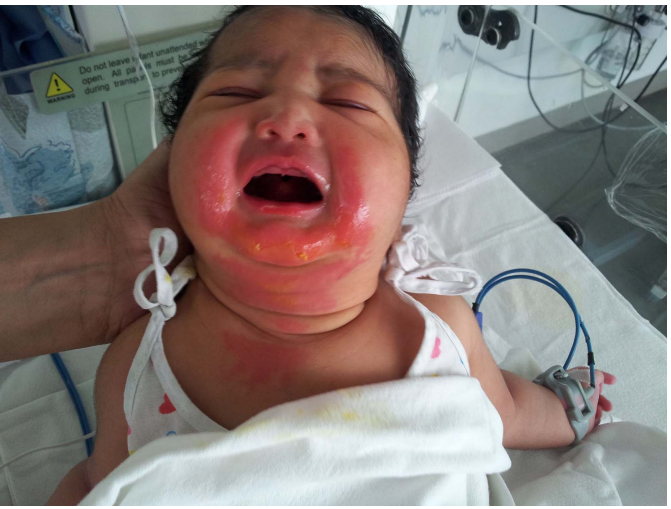

Figure 1 Perioral erythematous lesions on day 1 of life.

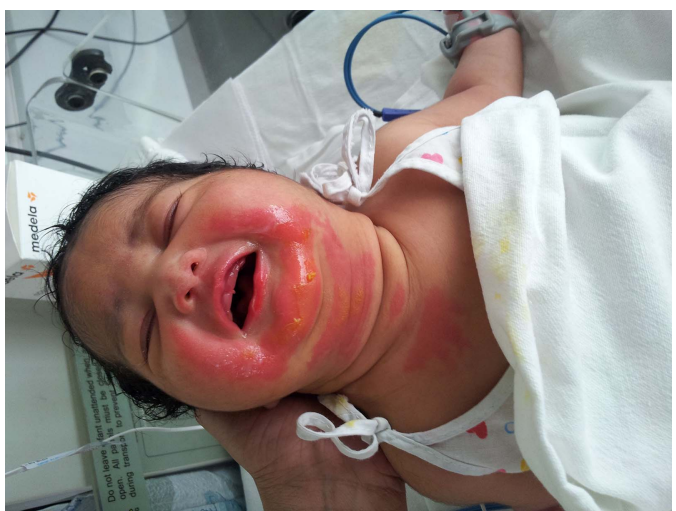

Figure 2 Erythematous painful lesions extending over face, neck and chest on day 1.

examination of symptoms such as honey-coloured crusting and history of the patient. Treatment is mainly antibiotics (local and systemic) and wound care. $^{34}$

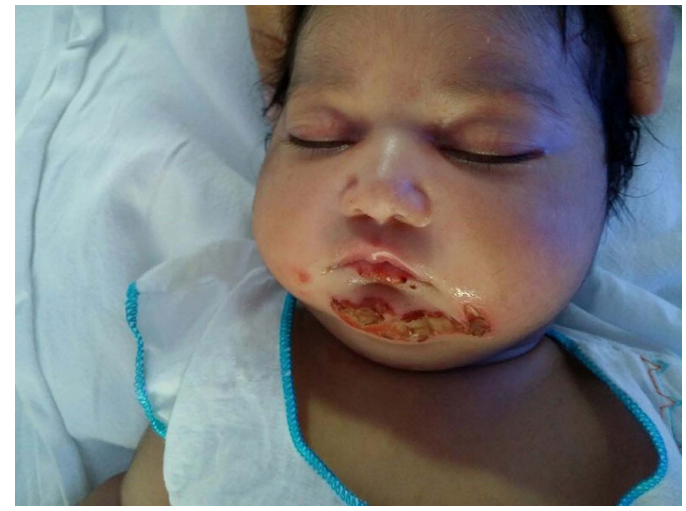

Figure 3 Healing lesions on day 3.

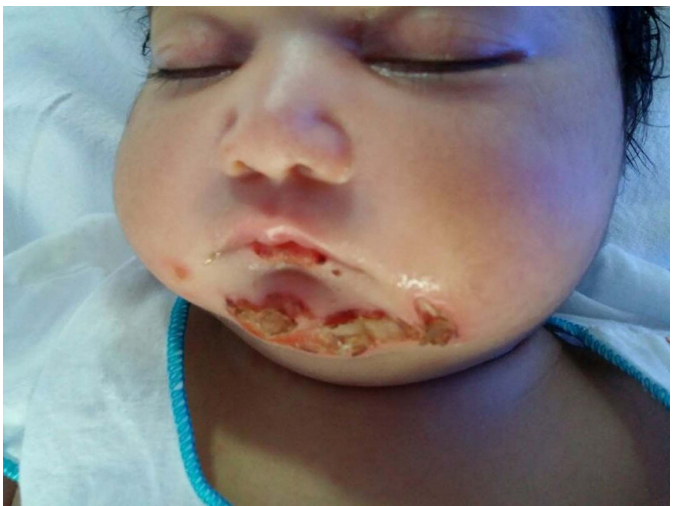

Figure 4 Appearance of honey crusting and disappearnce of erythema over neck and chest on day 3. 


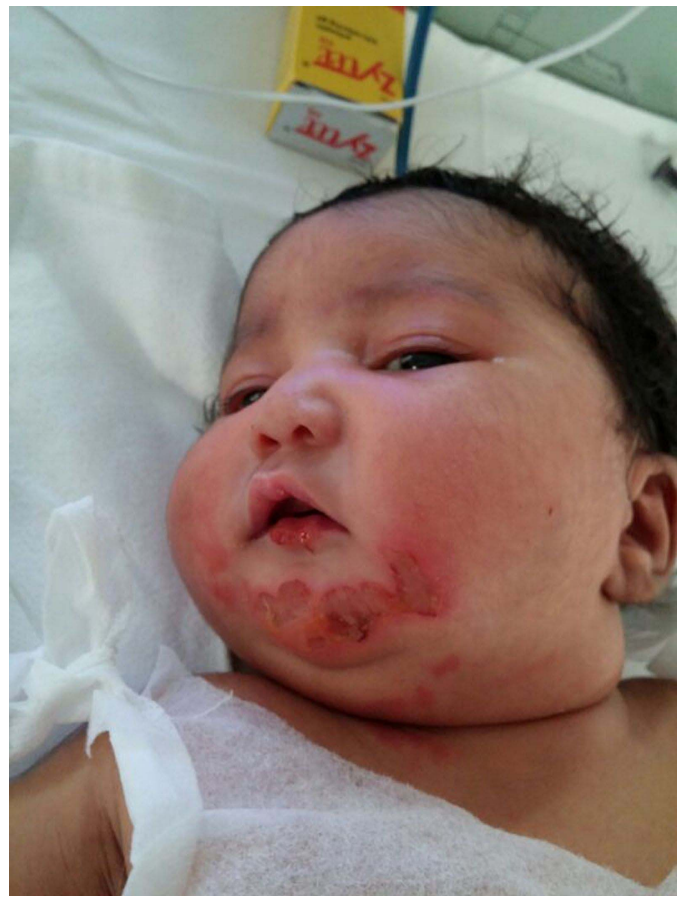

Figure 5 Healing lesions without scar formation on day 5.

Contributors DS wrote the primary manuscript. TP critically analysed the manuscript and made corrections. SM made the final corrections before submission.

\section{Learning points}

- Diagnosis is clinical. We should not wait for the culture/ sensitivity result as delay in starting treatment results in sepsis, which results in multiorgan failure.

- Maternal history should be examined for fever in the last week of pregnancy and prolonged rupture of membrane or any foul-smelling vaginal discharge.

- Appropriate antibiotics and wound care form the mainstay of treatment.

Competing interests None.

Patient consent Obtained.

Provenance and peer review Not commissioned; externally peer reviewed.

\section{REFERENCES}

1 Cole C, Gazewood J. Diagnosis and treatment of impetigo. Am Fam Physician 2007;75:859-64.

2 Hirschmann JV. Impetigo: etiology and therapy. Curr Clin Top Infect Dis 2002;22:42-51.

3 Kuniyuki S, Nakano K, Maekawa N, et al. Topical antibiotic treatment of impetigo with tetracycline. J Dermatol 2005;32:788-92.

4 [No authors listed]. Treating impetigo in primary care. Drug Ther Bull 2007:45:2-4.

Copyright 2014 BMJ Publishing Group. All rights reserved. For permission to reuse any of this content visit http://group.bmj.com/group/rights-licensing/permissions.

BMJ Case Report Fellows may re-use this article for personal use and teaching without any further permission.

Become a Fellow of BMJ Case Reports today and you can:

- Submit as many cases as you like

- Enjoy fast sympathetic peer review and rapid publication of accepted articles

- Access all the published articles

- Re-use any of the published material for personal use and teaching without further permission

For information on Institutional Fellowships contact consortiasales@bmjgroup.com

Visit casereports.bmj.com for more articles like this and to become a Fellow 